\title{
Lymphadenectomy in the subcarinal zone using a uniportal thoracoscopic approach: a narrative review
}

\author{
Takahiro Homma, Yoshifumi Shimada, Keitaro Tanabe \\ Department of General Thoracic and Cardiovascular Surgery, Graduate School of Medicine and Pharmaceutical Sciences, University of Toyama, \\ Toyama, Japan \\ Contributions: (I) Conception and design: T Homma; (II) Administrative support: T Homma; (III) Provision of study materials or patients: All \\ authors; (IV) Collection and assembly of data: All authors; (V) Data analysis and interpretation: T Homma; (VI) Manuscript writing: All authors; (VII) \\ Final approval of manuscript: All authors. \\ Correspondence to: Takahiro Homma. Department of General Thoracic and Cardiovascular Surgery, Graduate School of Medicine and Pharmaceutical \\ Sciences, University of Toyama, 2630 Sugitani, Toyama, Toyama 930-0194, Japan. Email: hommat@med.u-toyama.ac.jp.
}

\begin{abstract}
Objective: Our review aimed to provide an overview of the principle, anatomy, complications, and energy devices of subcarinal lymph node dissection and highlight the surgical technique for uniportal video-assisted thoracoscopic surgery.
\end{abstract}

Background: Lobectomy and lymph node dissection of the hilar and mediastinum are the standard surgical procedures for non-small cell lung cancer. The significance of lymph node dissection is to obtain an accurate staging and potential survival benefits. Certain subcarinal lymphadenectomy is essential to understanding the anatomy and energy devices.

Methods: We conducted a narrative review of the literature on subcarinal lymph node dissection. To that end, we searched PubMed for papers published until August 2021. Additional publications were identified in the references cited in the initial papers. We used theoretical considerations to characterize approaches and noted empirical findings, when available.

Conclusions: Although there are some surgical approach, the principles of procedures have not changed. Understanding the anatomy and energy devices is essential for en bloc and safe subcarinal dissection. In particular, the left side is deeper than the right side, and there are some tips and precautions. In the uniportal video-assisted thoracoscopic surgery, it is necessary to keep in mind to do it effectively with a small number of devices.

Keywords: Thoracic surgery; lymphadenectomy; dissection; uniportal; video-assisted thoracoscopic surgery

Received: 24 August 2021; Accepted: 13 October 2021; Published: 30 March 2022.

doi: 10.21037/asj-21-85

View this article at: https://dx.doi.org/10.21037/asj-21-85

\section{Introduction}

Based on the results of a clinical trial conducted in 1995, lobectomy and lymph node dissection of the hilar and mediastinum are the standard surgical procedures for nonsmall cell lung cancer (1). Minimally invasive approaches have been developed in the last decade, from conventional thoracotomy to video-assisted thoracoscopic surgery (VATS), robot-assisted thoracoscopic surgery, uniportal VATS, and the subxiphoid approach (2-4). Although each surgical approach has its own characteristics and advantages, the principles of these procedures have not changed and should still be performed in patients with lung cancer.

This manuscript covers the significance of lymph node dissection, anatomy, complications, energy devices, technical tips and pitfalls on lymphadenectomy in the subcarinal zone. In particular, the present study focused using uniportal VATS. We present the following article in accordance with the Narrative Review reporting checklist (available at https://asj.amegroups.com/article/ 
view/10.21037/asj-21-85/rc).

\section{Methods}

To identify the principle, anatomy, complications, and energy devices of subcarinal lymph node dissection, a literature search within the PubMed databases was conducted in August 2021. The search used the following terms 'lymph node', 'dissection', 'lymphadenectomy', 'lung cancer', 'subcarinal', 'thoracic surgery', 'video-assisted thoracoscopic surgery', 'thoracotomy', 'uniport', 'uniportal', 'single incision', 'single port', 'energy device', 'ultrasound', 'ultrasonic', 'bipolar', 'anatomy', 'complication', 'chylothorax', 'lymphatic vessels', 'thoracic duct' and 'surgical technique'. Papers published until the date of the review that contained these terms in the title or the abstract were selected. We limited our search to publications indexed as articles, proceedings papers or reviews, and then reviewed the references of the publications yielded by the search to identify additional relevant articles, which resulted in a total of 44 papers to be included in the review. The results and key information obtained were summarized by means of a narrative approach. We decided to categorize these articles based on five theoretical considerations; significance of lymph node dissection, anatomy, complications, energy devices, and surgical techniques.

\section{Discussion}

\section{Lymph node dissection}

Lymph node dissection is widely accepted as an important component of intrathoracic procedures. Regional nodal dissection using maps has been universally performed in lung cancer surgery (5). However, there are various types of lymph node dissection for lung cancer: systematic nodal dissection, selected lymph node biopsy, sampling, systematic sampling, lobe-specific systematic node dissection, and extended lymph node dissection $(6,7)$. Although various dissection types exist, the significance of lymph node dissection is to obtain an accurate staging and potential survival benefits.

Treatment policies differ depending on the stage of lung cancer. Some clinical trials evaluating the significance of adjuvant chemotherapy in patients with lung cancer have reported the survival benefit of postoperative chemotherapy for stage II and IIIA $(8,9)$. Therefore, an accurate stage determination is required. However, preoperative evaluation using computed tomography (CT) and positron emission tomography (PET) is not perfect. Meta-analyses have shown that the use of CT for assessing mediastinal nodal involvement has a sensitivity of $60-83 \%$, specificity of $77-82 \%$, and negative predictive value (NPV) of $85 \%(10-12)$. PET is considered to be the most sensitive and accurate non-invasive means of screening for lymph node involvement, with meta-analysis results showing a sensitivity of 79-88\%, specificity of $90-92 \%$, and NPV of 93\% (11-13).

Pathological node status was the most accurate and significant factor. Thus, pathological examination of the lymph nodes has also been developed. Typical examples include cervical mediastinoscopy (CM), endobronchial ultrasound (EBUS), and endoscopic esophageal ultrasound (EUS). The need for CM is still controversial, but combined EBUS- and EUS-guided biopsy has been recognized as the newer "gold standard" for mediastinal lymph node staging $(14,15)$.

These procedures have made it possible to make a more accurate diagnosis, but each procedure has some strengths and weaknesses, depending on the biopsy site, which was only collected from a part of a lymph node. Therefore, the greatest benefit of surgical dissection is said to be the potential survival benefit.

Even in clinical stage I patients after complete resection, clinicians sometimes experience relapse of lung cancer. Most reasons are thought to be due to a micro metastasis that already existed at the time of surgery. Lymph node dissection can not only prove accurate pathological node metastasis, but also achieve resectable local control. In particular, lymphadenectomy for unexpected N1 and N2 diseases is clinically important and effective. Patients with unexpected $\mathrm{N} 1$ disease have a better prognosis after complete resection with systematic lymph node dissection. They showed better survival than those with the expected N1 disease (16). The frequency of unexpected N2 disease is $12 \%$ (17), which is not small. The predictive factors of an unexpected $\mathrm{N} 2$ disease were a maximum standardized uptake value of the primary tumor $>3.0$ and $\mathrm{cN} 1$ disease (18). In surgical approach, even if lymph node metastasis is unexpectedly detected during surgery, there is no need to convert VATS to open thoracotomy (19).

\section{Anatomy}

Lymph node dissection is performed by excising all tissues in the compartment surrounded by anatomical tissue, 


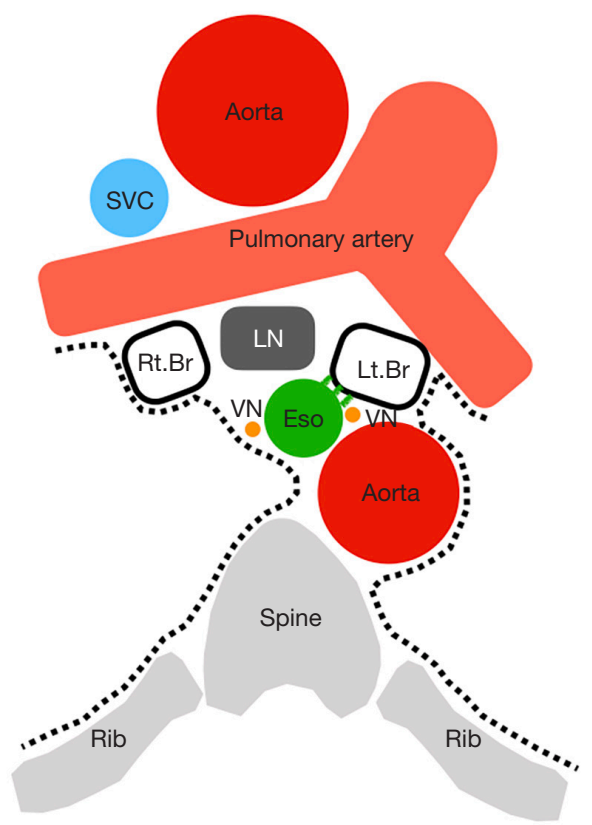

Figure 1 Subcarinal zone anatomy. SVC, superior vena cava; LN, lymph node; Rt., right; Lt., left; Br, bronchus; Eso, esophagus; VN, vagus nerve.

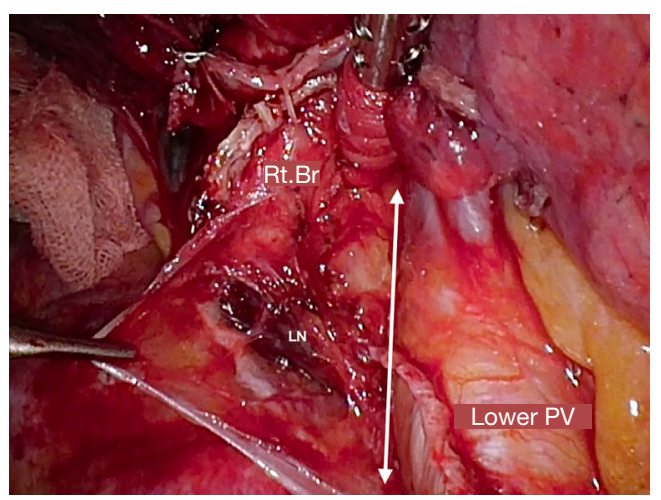

Figure 2 Intraoperative finding shows the cranial margin of the lower pulmonary vein considered to be the lower margin of dissection (white arrow). Rt., right; Br, bronchus; PV, pulmonary vein.

such as the trachea, bronchus, superior vena cava, aorta, pericardium, and esophagus.

Subcarinal lymph nodes are referred to as "station 7". The International Association for the Study of Lung Cancer (IASLC) lymph node map has described it as follows: "the upper border of station 7 is the carina of the trachea. The lower border of station 7 is the upper border of the lower lobe bronchus on the left and the lower border of the bronchus intermedium on the right" (20).

From an anatomical point of view, station 7 comprises the lymph nodes and surrounding tissues surrounded by the bilateral main bronchus, esophagus, pericardium, and bilateral mediastinal pleura, with the tracheal bifurcation as the apex (Figure 1). Included in the surrounding tissue structure and clinically important segments are the vagus nerve and its esophageal branches, tracheal branches, bronchial arteries, esophageal arteries, and thoracic duct. The definition of the IASLC lymph node map is based on CT images, with some dissociation in actual surgical findings. In particular, the lower edge of station 7 is defined by the bronchus on imaging, but clinically, the lower pulmonary vein is the boundary line (Figures 2,3 ).

The thoracic esophageal artery is distributed from the descending thoracic aorta to the anterior and posterior surfaces of the esophagus. The lymphatic path of the esophagus flows from the midpoint of the thoracic esophagus to the cranial side in the upper and caudal sides in the lower part. For innervation of the thoracic esophagus, the vagus nerves on both sides sprout many branches into the esophagus and interfere with each other to form the esophageal plexus. The sympathetic nerve also has branches in the esophageal plexus, but parasympathetic innervation still predominates (21).

The bronchial artery is a branch of the aorta that generally flows from the posterior surface. There are three main types of routes: type 1 (40.6\%) with one right bronchial artery and two left bronchial arteries, type 2 $(21.3 \%)$ with one bronchial artery on each side, and type 3 (20.6\%) with two bilateral bronchial arteries (22).

There are two main lymphatic channels in the bronchi and lungs (21). One is the peribronchial lymphatic plexus, which collects from the bronchi and most of the lung, and the subpleural lymphatic plexus, which collects from the visceral pleura of the lungs. The two communicate at the hilum, flow to the cranial side, and flow into the hilar and mediastinal lymph nodes. Innervation of the thoracic respiratory system is made up of the pulmonary plexus, which is composed of branches from both the bilateral vagus nerve and sympathetic nerve. The pulmonary plexus controls the bronchial diameter and glandular activity, as well as the thickness of pulmonary blood vessels.

The thoracic esophagus bulges to the left main bronchus and is in close contact with the left main bronchus. The two are strongly affected by fibroelastic membranes with sparse muscle fibers (23-25) (Figures 2,3). The bronchi and 


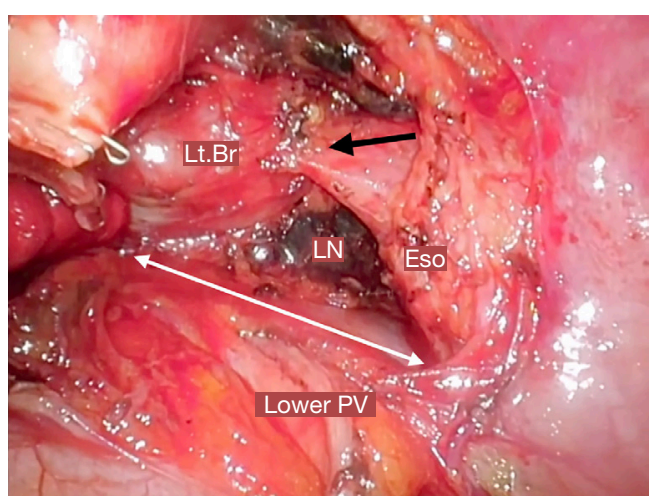

Figure 3 Intraoperative finding shows the cranial margin of the lower pulmonary vein considered to be the lower margin of dissection (white arrow) and fibroelastic membranes with sparse muscle fibers between the thoracic esophagus and the left main bronchus (black arrow). LN, lymph node; Lt. left; Br, bronchus; Eso, esophagus; PV, pulmonary vein.

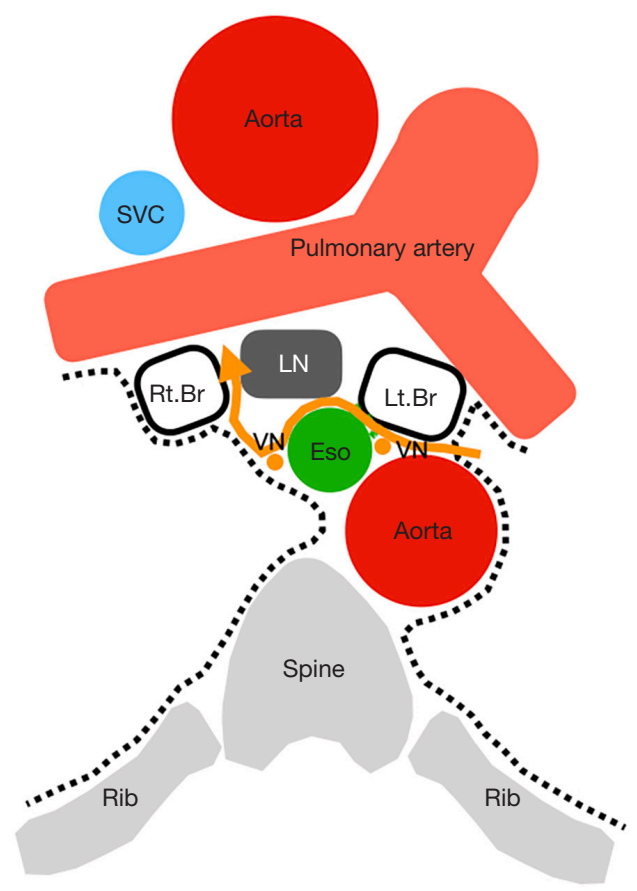

Figure 4 Representative image of the left side lymphadenectomy in the subcarinal zone. Dissection from the left side has a risk of damaging the bilateral vagal trunk. SVC, superior vena cava; LN, lymph node; Rt., right; Lt., left; Br, bronchus; Eso, esophagus; VN, vagus nerve. pericardium are anchored by a hard membranous tissue called the tracheobronchopericardial ligament (26).

\section{Complications}

Generally, because blood vessels, lymph vessels, and nerves run along the tissues surrounding the lymph nodes, the main complications associated with dissection include recurrent laryngeal nerve palsy, chylothorax, arrhythmia, and bleeding.

Possible complications of subcarinal node dissection include chylothorax, bleeding, bronchial injury, and esophageal injury from an anatomical point of view.

The frequency of chylothorax after lung cancer surgery is $0.25-3 \%$, with risk factors including extended resection, right side resection, and systematic lymph node dissection. The causal relationship between histology, stage, and postoperative chylothorax is controversial (27). Chylothorax is a complication that should be avoided because it requires reoperation and prolonged hospitalization.

Bleeding from subcarinal node dissection can be caused by the bronchial and esophageal arteries. According to reports of bleeding requiring reoperations after lung resection (28), intercostal arteries, lung parenchyma, aberrant vessels at the apex of the lung, and bronchial arteries were the causes of reoperations, but not esophageal artery. However, in subcarinal node dissection, bronchial and esophageal arteries are sometimes encountered. Since both branches are from the aorta, even small vessels, bleeding is eruptive resulting in poor surgical view and disorientation. However, excessive vascular closure can lead to organ ischemia. In particular, lymph node dissection associated with right lower lobectomy is a risk factor for bronchopleural fistulas (29).

Since the esophageal plexus is formed by complementing the vagus nerves on both sides with a large number of branches, cutting the branches around station 7 has no clinical effect. However, if both vagal trunks are damaged, sympathetic nerves dominate, leading to decreased esophageal peristalsis and decreased esophageal gland secretions, which may lead to gastrointestinal symptoms. In particular, subcarinal node dissection from the left side has a risk of damaging the bilateral vagal trunk (Figure 4). Direct injury to the bronchi and esophagus can result from anatomical misidentification or thermal damage from 
energy devices.

\section{Energy devices}

In the surgical treatment of lung cancer, energy devices have significantly contributed to the evolution and safety of surgical treatment, regardless of the procedure or approach. The improved vascular sealing function of advanced bipolar devices and ultrasonic energy devices is remarkable. These advanced energy devices alone can be safely used for vessels sized $\leq 5 \mathrm{~mm}$, regardless of whether they are pulmonary arteries or veins (30-36). If the size is $\geq 6 \mathrm{~mm}$, the pressure resistance will decrease; hence, it will be safer to secure the center with ligation or clip. Therefore, the esophageal and bronchial arteries can be safely dissected using these advanced devices alone.

In addition, advanced energy devices also have sufficient pressure resistance for thoracic duct treatment and are considered clinically acceptable (37-39). Prevention of postoperative chylothorax involves proper sealing of the lymphatic vessels. LigaSure is reportedly effective in short operations with a short drainage period compared with monopolar devices, and it is considered that the reliable sealing effect reduces drainage from lymphatic vessels (40).

Attention is focused on the lateral heat diffusion in the advanced bipolar and the high heat tip of the ultrasonic energy device. Because the tip temperature of the advanced bipolar device is controlled below $90^{\circ} \mathrm{C}$, the effect around the sealing tissue is minimal. Although the temperature of advanced bipolar devices is lower than that of ultrasonic devices, the thermal spread of advanced bipolar devices is greater than that induced by ultrasonic devices (41). Moreover, using advanced bipolar devices around nerves may have a risk of paralysis if the distance to the nerve is less than $3 \mathrm{~mm}$. On the other hand, the active blade of the ultrasonic energy device vibrates at a rate of $23-55 \mathrm{kHz}$. This effect is caused by the mechanical interaction between the oscillating tip of the device and tissue. Therefore, the tip temperature exceeded $100{ }^{\circ} \mathrm{C}(42)$. When handling ultrasound energy devices, surgeons should always focus on making contact with vital structures.

\section{Surgical technique of lymphadenectomy for subcarinal zone $(43,44)$}

\section{Right side}

The mediastinal pleura was cut from the lower pulmonary vein to the lower margin of the azygos vein. The lower edge of the subcarinal dissection is detached at the level of the cranial margin of the lower pulmonary vein and then exposed to the pericardium. Since the bronchi and pericardium are anchored by the tracheobronchopericardial ligament (26), it is necessary to peel this off to open the bifurcation. The esophageal side is peeled off while visually observing the vagal nerve trunk. The lymph nodes are grasped gently. Detachment along the anterior side of the esophagus can lead to the contralateral left bronchus, which is peeled off while maintaining the preservation of the bronchial artery, and proceeds toward the bronchial bifurcation (Figure $5 A$ ). When performing exfoliation on the esophageal side, lifting the right bronchi expands the field of view around the bifurcation. However, peeling on the right bronchi side is limited to a part. If all bronchial detachments are performed, the dissected lymph nodes may hang down and obstruct deep vision. If thin branches of blood vessels or nerves interfere with dissection, they are cut off as needed. In front of the tracheal bifurcation, the structure leading to station 4R (right lower paratracheal lymph node) is checked and cut off at the highest level of the bifurcation. Because this area includes bronchial arteries and lymph vessels, energy devices are effective for sealing. Careful management of these branches is important to prevent postoperative bleeding and chylothorax. The prominent vessels should be clipped or ligated before the nodes are removed completely.

One of the most important of subcarinal lymphadenectomy is proper retraction to achieve a good surgical view. Uniportal VATS has a limit on the number of instruments that can be inserted and the direction of traction. Cotton is very useful for lifting bronchi. When detached from the esophagus, grasping the dissected tissue with lymph node forceps and pressing it against the bronchial side is effective in continuously securing the surgical field and controlling the oozing of the dissected tissue.

\section{Left side}

The technique in the left is similar to the approach from the right side. The lung is retracted anteriorly, and the posterior mediastinal pleura is opened along the groove anterior to the descending aorta, which is retracted posteriorly. However, full exposure is more difficult on the left side because the subcarinal zone is anatomically located deeper compared to the right side. The mediastinal 

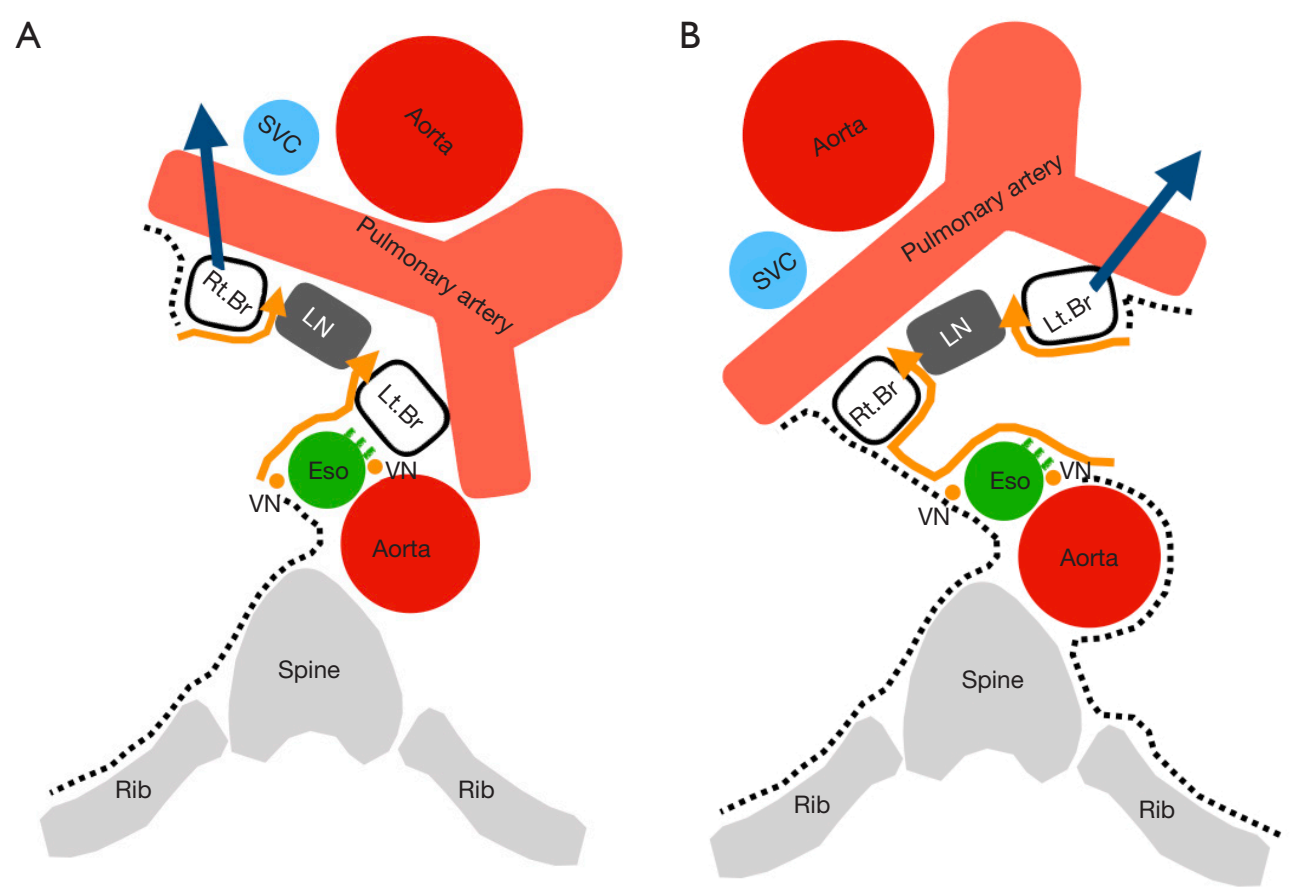

Figure 5 Raising the bronchus opens the tracheal bifurcation. (A) Right side, (B) left side. SVC, superior vena cava; LN, lymph node; Rt., right; Lt., left; Br, bronchus; Eso, esophagus; VN, vagus nerve.

pleura was cut from the lower pulmonary vein to the lower margin of the aortic arch. The lower edge of the subcarinal dissection is detached at the level of the cranial margin of the lower pulmonary vein and then exposed to the pericardium. As with the right side, it is necessary to peel off the tracheobronchopericardial ligament (26), and then peel off a part of the left bronchial side. The esophageal side was peeled off while visually observing the vagal nerve trunk. The bronchial side was peeled off toward the bronchial bifurcation. The difference from the right side is that the left side is farther and deeper than the right side to reach the tracheal bifurcation. Surgical field expansion is very important, and it is essential to lift the bronchi (Figure 5B). For this reason, it is sometimes necessary to break a membranous tissue between the esophagus and the left main bronchus (Figure 3), which is called a fibroelastic membrane with sparse muscle fibers (23-25). The contralateral, right mediastinal pleura and right vagus nerve can be identified by exfoliating the anterior part of the esophagus and proceeding deeper. Detachment along the contralateral mediastinal pleura can proceed to the contralateral right bronchus. At this time, care should be taken not to damage the esophagus or bronchi. When you reach the bifurcation, seal the bronchial arteries and lymph vessels and dissect the en bloc. Careful management of the vessels is important to prevent postoperative bleeding and chylothorax. The prominent vessels should be controlled with clip or ligation before the nodes are removed completely.

In uniportal VATS, as well as on the right side, cotton is useful for lifting the bronchi. When detached from the esophagus, grasping the dissected tissue with lymph node forceps and pressing it against the bronchial side is effective in continuously securing the surgical field and controlling the oozing of the dissected tissue. On the left side, surgical smoke is more likely to accumulate than on the right side, which causes a poor surgical field. Suction is increasingly used instead of cotton or lymph node forceps. In addition to cotton and lymph node forceps, suction is often used.

Subcarinal node dissection was located in the deepest part on both sides. For this reason, pleural effusion and blood generated by lobectomy tend to accumulate, which may obstruct the visual field. Some institutions perform subcarinal dissection prior to lobectomy. There is also a technique to widen the field by taping the lower pulmonary veins and bronchi, but in uniportal VATS, the tape may obstruct the field of vision. 


\section{Our uniportal VATS procedure}

Uniportal VATS port positions differed depending on the lobe. In the right upper and middle lobe, a port was placed at the fifth intercostal space at the mid-axillary line. The left upper lobe was similar to the right upper and middle lobe. In the right lower lobe, a port was placed at the sixth intercostal space at the post-axillary line. In the left lower lobe, a port was placed at the sixth intercostal space at the posterior-axillary line for the thoracoscope. Each port positions were placed by extending to the forward by $3 \mathrm{~cm}$ incision. Port sites were marked before surgery in preparation for conversion to multiportal VATS or thoracotomy. A thoracoscope was used a 30-degree, $5 \mathrm{~mm}$ camera (Endoeye, Olympus, Japan). A wound protector was inserted into the single access incision. Instruments were used curved surgical products. For lymph node dissection, a curved lung grasping clamp (Foerster lung grasping clamp, Scanlan), a curved suction instrument (Curved blunt tip, Wolf suction instruments, Scanlan), a forceps (Pro DeBakey Grasper, Geister, Germany and Aesculap uniport XS, B-Braun, Germany) and cotton rods (CS two-way handle, Unimedic, Japan) were essential. Energy devices were mainly used advanced bipolar devices (LigaSure, Covidien, USA and EnSeal, Ethicon, USA). A 20-Fr chest tube was inserted at the end of the procedure and was placed through the incision and the same intercostal space.

\section{Conclusions}

Understanding the anatomy and energy devices is essential for en bloc and safe subcarinal dissection. In particular, the left side is deeper than the right side, and there are some tips and precautions. The principle of uniportal VATS does not change, but it is necessary to keep in mind to do it effectively with a small number of items.

\section{Acknowledgments}

We would like to thank Dr. Kozo Nakanishi, Department of General Thoracic Surgery, National Hospital Organization Saitama Hospital, Japan, for the anatomy. We would also like to thank Editage (www.editage.com) for English language editing.

Funding: None.

\section{Footnote}

Provenance and Peer Review: This article was commissioned by the Guest Editor (Hitoshi Igai) for the series "Lymphadenectomy in Thoracoscopic Surgery" published in AME Surgical fournal. The article has undergone external peer review.

Reporting Checklist: The authors have completed the Narrative Review reporting checklist. Available at https:// asj.amegroups.com/article/view/10.21037/asj-21-85/rc

Conflicts of Interest: All authors have completed the ICMJE uniform disclosure form (available at https://asj.amegroups. com/article/view/10.21037/asj-21-85/coif). The series "Lymphadenectomy in Thoracoscopic Surgery" was commissioned by the editorial office without any funding or sponsorship. The authors have no other conflicts of interest to declare.

Ethical Statement: The authors are accountable for all aspects of the work in ensuring that questions related to the accuracy or integrity of any part of the work are appropriately investigated and resolved.

Open Access Statement: This is an Open Access article distributed in accordance with the Creative Commons Attribution-NonCommercial-NoDerivs 4.0 International License (CC BY-NC-ND 4.0), which permits the noncommercial replication and distribution of the article with the strict proviso that no changes or edits are made and the original work is properly cited (including links to both the formal publication through the relevant DOI and the license). See: https://creativecommons.org/licenses/by-nc-nd/4.0/.

\section{References}

1. Ginsberg RJ, Rubinstein LV. Randomized trial of lobectomy versus limited resection for T1 N0 non-small cell lung cancer. Lung Cancer Study Group. Ann Thorac Surg 1995;60:615-22; discussion 622-3.

2. Sihoe ADL. Uniportal Lung Cancer Surgery: State of the Evidence. Ann Thorac Surg 2019;107:962-72.

3. Veronesi G, Novellis P, Voulaz E, et al. Robot-assisted surgery for lung cancer: State of the art and perspectives. Lung Cancer 2016;101:28-34. 
4. Licht PB. Subxiphoid uniportal lobectomy. Eur J Cardiothorac Surg 2016;50:1067.

5. Pretreatment evaluation of non-small-cell lung cancer. The American Thoracic Society and The European Respiratory Society. Am J Respir Crit Care Med 1997;156:320-32.

6. Lardinois D, De Leyn P, Van Schil P, et al. ESTS guidelines for intraoperative lymph node staging in non-small cell lung cancer. Eur J Cardiothorac Surg 2006;30:787-92.

7. Watanabe S. Lymph node dissection for lung cancer: past, present, and future. Gen Thorac Cardiovasc Surg 2014;62:407-14.

8. Arriagada R, Bergman B, Dunant A, et al. Cisplatinbased adjuvant chemotherapy in patients with completely resected non-small-cell lung cancer. N Engl J Med 2004;350:351-60.

9. Winton T, Livingston R, Johnson D, et al. Vinorelbine plus cisplatin vs. observation in resected non-small-cell lung cancer. N Engl J Med 2005;352:2589-97.

10. Dales RE, Stark RM, Raman S. Computed tomography to stage lung cancer. Approaching a controversy using metaanalysis. Am Rev Respir Dis 1990;141:1096-101.

11. Dwamena BA, Sonnad SS, Angobaldo JO, et al. Metastases from non-small cell lung cancer: mediastinal staging in the 1990s--meta-analytic comparison of PET and CT. Radiology 1999;213:530-6.

12. Gould MK, Kuschner WG, Rydzak CE, et al. Test performance of positron emission tomography and computed tomography for mediastinal staging in patients with non-small-cell lung cancer: a meta-analysis. Ann Intern Med 2003;139:879-92.

13. Hellwig D, Ukena D, Paulsen F, et al. Meta-analysis of the efficacy of positron emission tomography with F-18fluorodeoxyglucose in lung tumors. Basis for discussion of the German Consensus Conference on PET in Oncology 2000. Pneumologie 2001;55:367-77.

14. Berania I, Kazakov J, Khereba M, et al. Endoscopic Mediastinal Staging in Lung Cancer Is Superior to "Gold Standard" Surgical Staging. Ann Thorac Surg 2016;101:547-50.

15. Vilmann P, Clementsen PF, Colella S, et al. Combined endobronchial and esophageal endosonography for the diagnosis and staging of lung cancer: European Society of Gastrointestinal Endoscopy (ESGE) Guideline, in cooperation with the European Respiratory Society (ERS) and the European Society of Thoracic Surgeons (ESTS). Endoscopy 2015;47:545-59.

16. Shin S, Kim HK, Choi YS, et al. Prognosis of unexpected and expected pathologic N1 non-small cell lung cancer. Ann Thorac Surg 2013;96:969-75; discussion 975-6.

17. Fiorelli A, Sagan D, Mackiewicz L, et al. Incidence, Risk Factors, and Analysis of Survival of Unexpected N2 Disease in Stage I Non-Small Cell Lung Cancer. Thorac Cardiovasc Surg 2015;63:558-67.

18. Kamigaichi A, Tsutani Y, Mimae T, et al. Prediction of Unexpected N2 Disease Associated With Clinical T12N0-1M0 Non-Small-Cell Lung Cancer. Clin Lung Cancer 2021;22:120-126.e3.

19. Zhou W, Chen X, Zhang H, et al. Video-assisted thoracic surgery lobectomy for unexpected pathologic N2 nonsmall cell lung cancer. Thorac Cancer 2013;4:287-94.

20. El-Sherief AH, Lau CT, Wu CC, et al. International association for the study of lung cancer (IASLC) lymph node map: radiologic review with CT illustration. Radiographics 2014;34:1680-91.

21. Schuenke M, Schulte E, Schumacher U. THIEME Atlas of Anatomy. Internal Organs. Gerorg Thieme Verlag, Stuttgart, Germany.

22. Walker CM, Rosado-de-Christenson ML, MartínezJiménez S, et al. Bronchial arteries: anatomy, function, hypertrophy, and anomalies. Radiographics 2015;35:32-49.

23. Agur AMR, Dalley AF. Grant's atlas of anatomy. 12th ed. Lippincott Williams \& Wilkins, a Welters Kluwer Business. 2009

24. Netter FH. Atlas of human anatomy, 7th ed. Elsevier Inc. 2019

25. Mangi AA, Gaissert HA, Wright CD, et al. Benign broncho-esophageal fistula in the adult. Ann Thorac Surg 2002;73:911-5.

26. Nakanishi K, Goto H, Ito T. Fascial reinforcement fixing the bronchi to the heart: its anatomy and clinical significance. Surg Radiol Anat 2017;39:1301-8.

27. Chen C, Wang Z, Hao J, et al. Chylothorax after Lung Cancer Surgery: A Key Factor Influencing Prognosis and Quality of Life. Ann Thorac Cardiovasc Surg 2020;26:303-10.

28. Yano M, Numanami H, Akiyama T, et al. Reoperation for postoperative bleeding following pulmonary resection: a report of a single-center experience. Gen Thorac Cardiovasc Surg 2019;67:608-14.

29. Okuda M, Go T, Yokomise H. Risk factor of bronchopleural fistula after general thoracic surgery: review article. Gen Thorac Cardiovasc Surg 2017;65:679-85.

30. Homma T. Advances and safe use of energy devices in lung cancer surgery. Cancers 2021. In press. 
31. Okada M, Miyata Y, Takamochi K, et al. Prospective feasibility study of sealing pulmonary vessels with energy in lung surgery. J Thorac Cardiovasc Surg 2019;157:388-95.

32. Liberman M, Khereba M, Nasir B, et al. Pulmonary Artery Sealing Using the HARMONIC ACE+ Shears for VideoAssisted Thoracoscopic Surgery Lobectomy. Ann Thorac Surg 2015;100:898-903; discussion 903-4.

33. Lesser TG, Wolfram F, Boltze C. Sealing of pulmonary arteries with LigaSure: in vivo and ex vivo examinations. J Thorac Cardiovasc Surg 2013;145:1525-8.

34. Yamada T, Sowa T, Bando T, et al. Experimental study in pulmonary artery sealing with a vessel-sealing device. Asian Cardiovasc Thorac Ann 2016;24:562-7.

35. Lucchi M, Duranti L, Melfi F, et al. Polymer self-locking clips for vascular control during minimally invasive pulmonary lobectomies. J Thorac Cardiovasc Surg 2010;139:1345-6, 1346.e1.

36. Harold KL, Pollinger H, Matthews BD, et al. Comparison of ultrasonic energy, bipolar thermal energy, and vascular clips for the hemostasis of small-, medium-, and largesized arteries. Surg Endosc 2003;17:1228-30.

37. Novitsky YW, Rosen MJ, Harrell AG, et al. Evaluation of the efficacy of the electrosurgical bipolar vessel sealer (LigaSure) devices in sealing lymphatic vessels. Surg Innov 2005;12:155-60.

doi: $10.21037 /$ asj-21-85

Cite this article as: Homma T, Shimada Y, Tanabe K. Lymphadenectomy in the subcarinal zone using a uniportal thoracoscopic approach: a narrative review. AME Surg J 2022;2:6.
38. Nakayama H, Ito H, Kato Y, et al. Ultrasonic scalpel for sealing of the thoracic duct: evaluation of effectiveness in an animal model. Interact Cardiovasc Thorac Surg 2009;9:399-401.

39. Kajiyama Y, Iwanuma Y, Tomita N, et al. Sealing the thoracic duct with ultrasonic coagulating shears. Hepatogastroenterology 2005;52:1053-6.

40. Martucci N, Tracey M, La Rocca A, et al. A pilot prospective randomized, controlled trial comparing LigaSure $^{\mathrm{TM}}$ tissue fusion technology with the Force Triad ${ }^{\mathrm{TM}}$ energy platform to the electrosurgical pencil on rates of atrial fibrillation after pulmonary lobectomy and mediastinal lymphadenectomy. Eur J Cardiothorac Surg 2015;47:e13-8.

41. Hayami M, Watanabe M, Mine S, et al. Lateral thermal spread induced by energy devices: a porcine model to evaluate the influence on the recurrent laryngeal nerve. Surg Endosc 2019;33:4153-63.

42. Feldman LS, Fuchshuber PR, Jones DB. The SAGES Manual on the Fundamental Use of Surgical Energy (FUSE). Springer, New York, NY, USA.

43. Kuzdal J. ESTS textbook of thoracic surgery. Medycyna Praktyczna, Cracow 2014.

44. Sugarbaker DJ. Adult chest surgery. The McGraw-Hill companies, New York, NY, USA. 